\title{
Hepatitis E Virus Nanoparticle Encapsulating Nano-Theranostic Reagent as Modularized Capsule
}

\author{
Chun-Chieh Chen, Marie Stark, Mo A Baikoghli and R Holland Cheng* \\ Department of Molecular and Cellular Biology, University of California, USA
}

Submission: June 01, 2017; Published: June 13, 2017

"Corresponding author: R Holland Cheng, Department of Molecular and Cellular Biology, University of California, Davis, California 95616, 1 Shields Ave., Davis, CA 95616, USA, Tel: 15307525659; Fax: 15307523085; Email: rhch@ucdavis.edu

\begin{abstract}
A modularized theranostic capsule, Hepatitis E Virus Nanoparticle (HEVNP), derived from the HEV virus-like particle (VLP), is proposed as a multifunctional platform for cancer targeting, imaging and therapeutic applications. This can be achieved by utilizing the flexible domain of HEVNPs to conjugate different functional peptides and/or compounds to capsule surface, and simultaneously encapsulate drugs, DNA/RNA, or even inorganic beads into its interior. In prior research, breast cancer tumor targeting with a HEVNP capsule diagnostic was demonstrated by chemically conjugating a breast cancer cell-specific ligand and a near-infrared (NIR) fluorescence dye to its surface for diagnostic imaging. Here, we further explore applications of the modularized theranostic capsule by encapsulating ferrite nano-particles into the HEVNP interior for MRI detection and hyperthermia treatment.
\end{abstract}

Keywords: Hepatitis E virus-like particle; VLP encapsulation; Nanoparticle; MRI; Hyperthermia

\section{Nanoparticles as Targeted Drug Delivery Carrier}

The application of nanoparticles in targeted drug delivery has dramatically increased in recent years. Nanocarriers including synthetic polymers, liposomes, and telodendrimers have been proposed and investigated thoroughly. However, a need remains to address several limitations such as, toxicity, inability to accumulate a sufficient number of molecules to the cytoplasm through target cell internalization, and lack of controlled biodegradation [1,2]. In contrast, virus-like particles (VLPs) possess advantages in efficient penetration of cells by active endocytosis, polyvalence to anchor multiple copies of active agents, and biocompatibility, undergoing proteolytic decay after delivery.

Hepatitis E Virus Nanoparticles (HEVNPs) as NanoCapsule Delivery Platform

Hepatitis E Virus Nanoparticles (HEVNPs), derived from a modified form of the HEV virus like particles (VLPs), are noninfectious, self-assembling nanoparticles capable of cell-binding and entry. In addition, HEVNP maintains its structure integrity of virus like particle in low-pH environment [3], an advantage for intratumoral penetration. The baculovirus expression vector-based production of HEV capsid protein, PORF2, in commercially-available insect High Five cells generates HEVNPs that are easily purified at high yield and low cost [4]. HEVNPs form a hollow, $\mathrm{T}=1$ icosohedral capsid, composed of 60 identical units [5], rendering it highly stable both in storage and in harsh physiological conditions. Additionally, HEVNPs possess a surface exposed protrusion domain (P domain) connected through a flexible hinge to a stable icosahedral base. Meanwhile, the surface engineering of cysteine replacement on P domain can not only be used as chemical conjugation sites, but also to reduce the recognition of pre-existing HEV-specific antibodies to VLPs [6], the major shortcoming for protein based delivery vector. With 60 repeated units of capsid proteins, single site-specific modification on $\mathrm{P}$ domain results in 60 symmetric sites for chemical modulation of multiple foreign molecules.

\section{HEVNPs as Oral Delivery System}

Like the native virus, HEVNP is stable in acidic environment [3] and resistant to proteolytic digestion [7], thus it poses a great advantage as an oral delivery vehicle. In fact, oral administration of HEVNP elicits both systemic and mucosal immunity with undetectable tolerance, and protective immunity against HEV challenge in non-human primates [8]. Chimeric HEVNPs carrying a foreign epitope can elicit mucosal and systemic antibodies 
against both HEV and the foreign epitope after oral administration [9]. Importantly, HEVNP can orally deliver plasmid DNA to the epithelial cells of the small intestine and induce antibody and cytotoxic $\mathrm{T}$ lymphocyte (CTL) responses against the plasmid encoded antigen [10]. These studies establish the feasibility of utilizing HEVNP for mucosal delivery, in a route resembling virus native transmission.

\section{Applications of Chemical Activated Nanocapsids}

Cancer theranostics requires direct contact of drug with pathological foci; therefore, a capsule carrying specific ligands is preferential for targeted delivery of anti-cancer reagents. In previous study, we created a HEVNP based theranostic capsule whose entry specificity can be defined by the HEVNP-conjugated targeting ligand. The engineered HEVNP after conjugation with
LXY30, a ligand peptide with a high affinity for human malignant breast tumor cells [11], showed specific targeting to breast tumor cell both in vitro and in vivo, indicating that delivery route of virus-like particle can be manipulated to facilitate targeted delivery of diagnostic or therapeutic reagents to pathologic foci. In prior research, two different conjugation methods were utilized to demonstrate the variant reactive capability of surface modified HEVNPs. A thiol-selective conjugation was used for coupling cancer ligand onto HEVNPs. Meanwhile, the fluorescence dye was conjugated by amine-selective conjugation in order to generate sufficient NIR signal to detect HEVNP distribution in breast cancer cells/tumors and mice. Therefore, the HEVNP can be used as a dual-functional platform, tagging with cancer adhesion-ligand concomitantly with detection marker, for cancer diagnosis $[6,12,13]$.

\section{The Encapsulation Capability of HEVNPs}

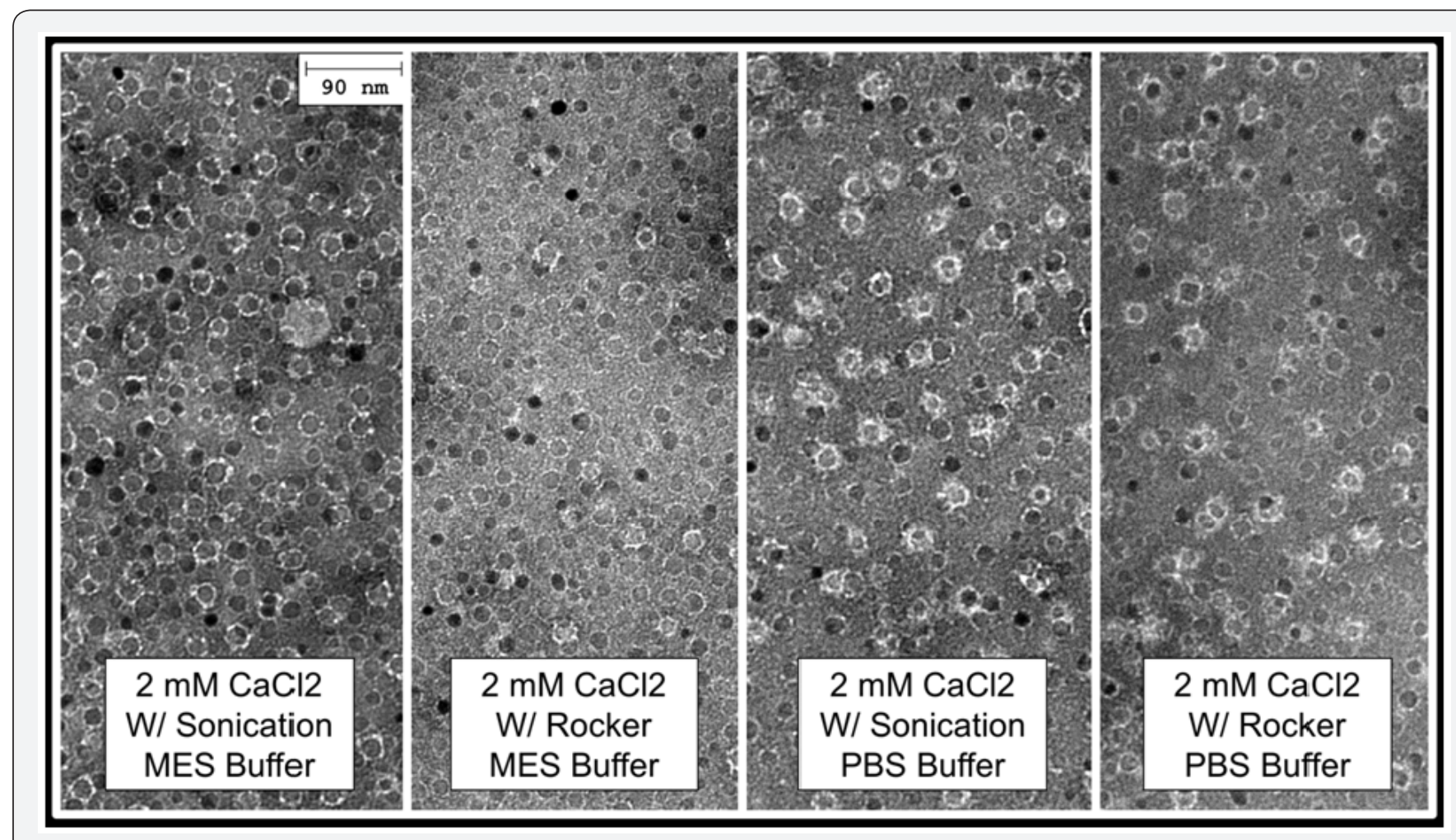

Figure 1: The encapsulation of ferrite into HEVNPs in 0.01M MES buffer, $\mathrm{pH} 6.2,2 \mathrm{mM} \mathrm{CaCl}_{2}$, with sonication (A). in $0.01 \mathrm{M} \mathrm{MES} \mathrm{buffer,} \mathrm{pH} \mathrm{6.2,}$

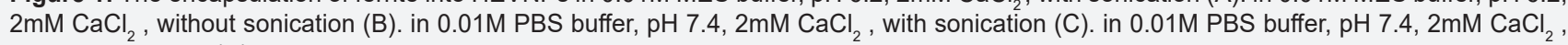
without sonication (D).

In addition to conjugating cancer-cell targeting ligand on the surface, the utilization of modularized theranostic capsule can be expanded by using the interior space of HEVNPs. HEVNPs can be reversibly disassembled and reassembled through chemical reduction and chelation, providing a method to encapsulate theranostic nanomaterials in vitro. Specifically, HEVNPs will disassemble in the presence of reducing and chelating reagents such as dithiothreitol (DTT) and Ethylenediaminetetraacetic acid (EDTA) or Ethylene glycol-bis( $\beta$-aminoethyl ether)$\mathrm{N}, \mathrm{N}, \mathrm{N}$,'N'-tetraacetic acid (EGTA). The HEVNP reassembly can be triggered by the calcium ion concentration. A DNA vaccine was proposed using HEVNP encapsulating foreign DNA to stimulate mucosal and systemic immune response by oral administration [10]. In addition, HEVNP is capable of encapsulation of magnetic nanoparticles such as ferrite (Figure 1), for both diagnosis under MRI and tumor-targeted hyperthermia induced by ultrasonic or radio frequency electromagnetic radiation [14] (Figure 2). Iron oxide nanoparticle enapsulation has been demonstrated with plant-based Brome Mosaic Virus nanoparticles (BMVNPs) through $\mathrm{pH}$ adjustment at the appropriate ionic strength. Unlike 
HEVNPs, BMV nanoparticles are generated through pH-based disassembly and manual extraction of RNA, such that icosahedral assemblies have not been optimized for non-infectious proteinbased production and self-assembly of stable virus-like particles [2]. Conversely, the HEVNP sequence has been optimized to not encapsulate virus-RNA, forming highly stable non-infectious capsids capable of reversible in vitro assembly through cation mediation. As an expansion of the HEV encapsulation research, negatively charged micro-RNA/siRNA could be also encapsulated into the interior of HEVNPs for gene silencing. The encapsulation capability of HEVNP provides broad possibilities for drug or gene delivery [13].

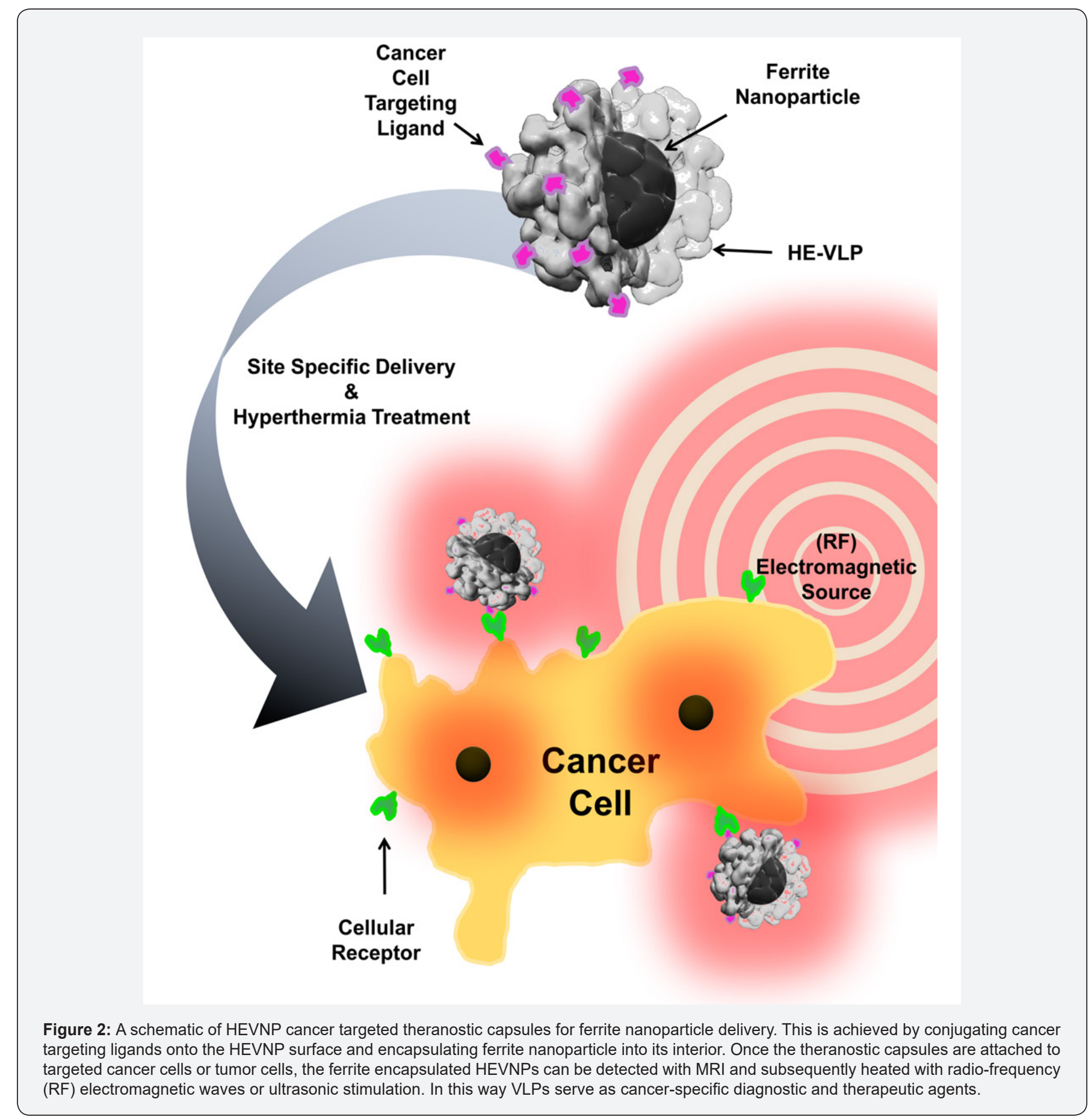

By binding the cancer cell targeting ligand on its surface, HEVNP could have potential applications in cancer cell targeting gene therapy; consequently, this would improve current treatments used in cancer patients. The capsid completeness protects drug from early release so as to enhance drug permeability and retention, a major limitation in effective cancer therapy. Therefore, the successful tumor targeting and encapsulation capability of HEVNP could be used as modularized 
theranostic nano-capusule in various medical applications from oral vaccine, cancer imaging, tumor-directed hyperthermia treatment, organ/tissue targeting gene therapy, and other therapeutics lacking of targeting capability.

\section{Acknowledgment}

The authors acknowledge the sponsorship of the funding to RHC by NIH grant \#'s: AI095382, EB021230, CA198880, National Institute of Food and Agriculture, as well as Finland Distinguished Professor program.

\section{References}

1. Sebestik J, Niederhafner P, Jezek J (2011) Peptide and glycopeptide dendrimers and analogous dendrimeric structures and their biomedical applications. Amino acids 40(2): 301-370.

2. Jian F, Zhang Y, Wang J, Ba K, Mao R, et al. (2012) Toxicity of biodegradable nanoscale preparations. Current drug metabolism 13: 440-446.

3. Zafrullah M, Khursheed Z, Yadav S, Sahgal D, Jameel S, et al. (2004) Acidic $\mathrm{pH}$ enhances structure and structural stability of the capsid protein of hepatitis E virus. Biochem Biophys Res Commun 313(1): 67-73.

4. Kawano M, Xing L, Lam KS, Handa H, Miyamura T, et al. (2011) Design platforms of nanocapsules for human therapeutics or vaccine in Singh and I. K. Srivastava (Eds.), Development of Vaccines Wiley Pub pp. 125140.

5. Xing L, Kato K, Li T, Takeda N, Miyamura T, et al. (1999) Recombinant hepatitis E capsid protein self-assembles into a dual-domain $\mathrm{T}=1$ particle presenting native virus epitopes. Virology 265(1): 35-45.

6. Chen CC, Xing L, Stark M1, Ou T1, Holla P, et al. (2016) Chemically activatable viral capsid functionalized for cancer targeting. Nanomedicine (Lond) 11(4): 377-390.

7. Jariyapong P, Xing L, van Houten NE, Li TC, Weerachatyanukul W, et al. (2013) Chimeric hepatitis E virus-like particle as a carrier for oraldelivery. Vaccine 31(2): 417-424.

8. Li TC, Suzaki Y, Ami Y, Dhole TN, Miyamura T (2004) Protection of cynomolgus monkeys against HEV infection by oral administration of recombinant hepatitis E virus-like particles. Vaccine 22(3-4): 370-377.

9. Niikura M, Takamura S, Kim G, Kawai S, Saijo M, et al. (2002) Chimeric recombinant hepatitis $\mathrm{E}$ virus-like particles as an oral vaccine vehicle presenting foreign epitopes. Virology 293(2): 273-280.

10. Takamura S, Niikura M, Li TC, Takeda N, Kusagawa S, et al. (2004) DNA vaccine-encapsulated virus-like particles derived from an orally transmissible virus stimulate mucosal and systemic immune responses by oral administration. Gene therapy 11(7): 628-635.

11. Yao N, Xiao W, Wang X, Marik J, Park SH, et al. (2009) Discovery of targeting ligands for breast cancer cells using the one-bead onecompound combinatorial method. Journal of medicinal chemistry 52(1): 126-133.

12. Li X1, Xu X, Jin A, Jia Q Zhou H, et al. (2013) Self-assembled virus-like particles with magnetic cores. Nano letters 7: 2407-2416.

13. Stark M, Cheng RH (2016) Surface modulatable nanocapsids for targeting and tracking toward nanotheranostic delivery. Pharmaceutical patent analyst 5(5): 307-317.

14. Roemer RB (1999) Engineering aspects of hyperthermia therapy. Annual review of biomedical engineering 1: 347-376.

\section{Your next submission with JuniperPublishers will reach you the below assets}

- Quality Editorial service

- Swift Peer Review

- Reprints availability

- E-prints Service

- Manuscript Podcast for convenient understanding

- Global attainment for your research

- Manuscript accessibility in different formats

( Pdf, E-pub, Full Text, audio)

- Unceasing customer service

Track the below URL for one-step submission https://juniperpublishers.com/online-submission.php 